\title{
Oxidative stress induces insulin resistance by activating the nuclear factor- $\kappa$ B pathway and disrupting normal subcellular distribution of phosphatidylinositol 3-kinase
}

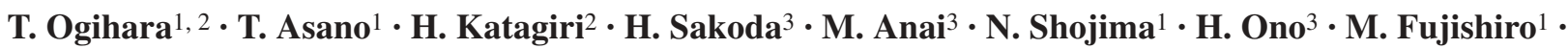 \\ A. Kushiyama ${ }^{1}$ Y. Fukushima ${ }^{1}$ M. Kikuchi ${ }^{3}$ N. Noguchi $^{4} \cdot$ H. Aburatani ${ }^{4} \cdot$ Y. Gotoh $^{5} \cdot$ I. Komuro $^{6} \cdot$ T. Fujita $^{1}$ \\ ${ }^{1}$ Department of Internal Medicine, Graduate School of Medicine, University of Tokyo, Tokyo, Japan \\ ${ }^{2}$ Division of Advanced Therapeutics for Metabolic Diseases, Center for Translational and Advanced Animal Research \\ on Human Diseases, Tohoku University Graduate School of Medicine, Sendai, Japan \\ 3 The Institute for Adult Diseases, Asahi Life Foundation, Tokyo, Japan \\ ${ }^{4}$ Research Center for Advanced Science and Technology, University of Tokyo, Tokyo, Japan \\ ${ }_{5}^{5}$ Department of Molecular Biology, Institute of Molecular and Cellular Biosciences, University of Tokyo, Tokyo, Japan \\ ${ }^{6}$ Department of Cardiovascular Science and Medicine, Chiba University Graduate School of Medicine, Chiba, Japan
}

\begin{abstract}
Aims/hypothesis. Oxidative stress is associated with diabetes, hypertension and atherosclerosis. Insulin resistance is implicated in the development of these disorders. We tested the hypothesis that oxidative stress induces insulin resistance in rats, and endeavoured to identify mechanisms linking the two.

Methods. Buthionine sulfoximine (BSO), an inhibitor of glutathione synthase, was administered to SpragueDawley rats and 3T3-L1 adipocytes. Glucose metabolism and insulin signalling both in vivo and in 3T3-L1 adipocytes were examined. In 3T3-L1 adipocytes, the effects of overexpression of a dominant negative mutant of inhibitory $\kappa \mathrm{B}(\mathrm{I} \kappa \mathrm{B})$, one role of which is to block oxidative-stress-induced nuclear factor (NF)- $\mathrm{KB}$ activation, were investigated.

Results. In rats given BSO for 2 weeks, the plasma lipid hydroperoxide level doubled, indicating increased oxidative stress. A hyperinsulinaemic-euglycaemic clamp study and a glucose transport assay using isolated muscle and adipocytes revealed insulin
\end{abstract}

resistance in BSO-treated rats. BSO treatment also impaired insulin-induced glucose uptake and GLUT4 translocation in 3T3-L1 adipocytes. In BSO-treated rat muscle, adipose tissue and 3T3-L1 adipocytes, insulin-induced IRS-1 phosphorylation in the low-density microsome (LDM) fraction was specifically decreased, while that in whole cell lysates was not altered, and subsequent translocation of phosphatidylinositol (PI) 3-kinase from the cytosol and the LDM fraction was disrupted. BSO-induced impairments of insulin action and insulin signalling were reversed by overexpressing the dominant negative mutant of I $\mathrm{BB}$, thereby suppressing NF- $\kappa \mathrm{B}$ activation.

Conclusions/interpretation. Oxidative stress induces insulin resistance by impairing IRS-1 phosphorylation and PI 3-kinase activation in the LDM fraction, and NF- $\kappa B$ activation is likely to be involved in this process.

Keywords Buthionine sulfoximine - Glutathione · Hyperinsulinaemic-euglycaemic clamp · Inhibitory $\mathrm{\kappa B}$. Insulin resistance $\cdot$ IRS $\cdot$ Nuclear factor- $\kappa \mathrm{B} \cdot$ Oxidative stress $\cdot$ Phosphatidylinositol 3-kinase
Received: 20 October 2003 / Accepted: 26 January 2004

Published online: 1 May 2004

C) Springer-Verlag 2004

T. Asano (-

Department of Internal Medicine, Graduate School of Medicine,

University of Tokyo, Tokyo 113-8655, Japan

E-mail: asano-tky@umin.ac.jp

Tel.: +81-3-38153411 ext. 33133, Fax: +81-3-58031874

Present address:

T. Asano

Department of Physiological Chemistry and Metabolism,

Graduate School of Medicine, University of Tokyo,

Tokyo 113-8655, Japan

\section{Introduction}

Oxidative stress represents an imbalance between production of reactive oxygen species and the antioxidant defence system [1]. Oxidative stress is widely recognised as being associated with various disorders including diabetes, hypertension and atherosclerosis. In-

Abbreviations: BSO, buthionine sulfoximine - GMSA, gel mobility shift assay $\cdot \mathrm{I} \kappa \mathrm{B}$, inhibitory $\kappa \mathrm{B} \cdot \mathrm{IKK}, \mathrm{I} \kappa \mathrm{B}$ kinase $\cdot$ LDM, low-density microsome $\cdot \mathrm{NF}-\kappa \mathrm{B}$, nuclear factor- $\kappa \mathrm{B} \cdot$ PI, phosphatidylinositol 
sulin resistance is a common feature of these disorders $[2,3]$. Indeed, in diabetic people and in animal models of diabetes, the plasma free radical concentration is increased $[4,5]$ and antioxidant defences are diminished $[6,7]$. It has also been suggested that antioxidant agents such as vitamin $C$ [8] and E [9] improve insulin action in diabetic subjects.

Angiotensin II reportedly induces free radical production and increases plasma oxidative stress [10]. In our previous study, we showed continuous infusion of angiotensin II to induce insulin resistance with increased oxidative stress in rats, while the spin trap agent tempol [11], which works as a superoxide dismutase mimetic, decreases oxidative stress and improves insulin resistance in these rats [12]. A similar coexistence of oxidative stress and insulin resistance, as well as recovery with tempol administration was observed in adrenomedullin-deficient mice [13]. These previous reports strongly suggest a close relationship between oxidative stress and insulin resistance. Thus, we attempted to elucidate the molecular mechanisms underlying insulin resistance and oxidative stress.

In this study, to increase oxidative stress in vivo, we utilised a selective inhibitor of $\gamma$-glutamylcysteine synthetase, i.e. an inhibitor of glutathione synthase, buthionine sulfoximine (BSO). Glutathione is one of the major components of the antioxidant defence system, such that BSO administration increases oxidative stress by reducing the tissue glutathione level [14]. Although BSO does not have toxic effects in animals [14], BSO-treated rats were previously shown to exhibit glucose intolerance [15] and hypertension [16]. In the current study, we examined the effect of BSO treatment on insulin resistance in rats and 3T3-L1 adipocytes. We investigated the molecular mechanisms underlying BSO-induced insulin resistance, focusing on the subcellular distribution of phosphatidylinositol (PI) 3-kinase. Finally, we examined the involvement of the nuclear factor (NF)- $\kappa \mathrm{B}$ pathway in BSO-induced insulin resistance and insulin signalling impairment.

\section{Materials and methods}

Materials. Affinity-purified antibodies against IRS-1 and GLUT4 were prepared as previously described [17]. Antibodies against phosphotyrosine, the p85 subunit of PI 3-kinase, and inhibitory $\kappa \mathrm{B}(\mathrm{I} \kappa \mathrm{B})$ were purchased from Upstate Biotechnology (Milton Keynes, UK). TNF- $\alpha$ and buthionine-[S, R]sulfoximine (BSO) were purchased from Sigma-Aldrich (St. Louis, Mo., USA).

Animals. Seven-week-old male Sprague-Dawley rats (Tokyo Experimental Animals, Tokyo, Japan) were fed a standard rodent diet with or without water containing $30 \mathrm{mmol} / \mathrm{l} \mathrm{BSO}$ for 14 days [16]. The animal care was in accordance with the policies of the University of Tokyo, and the "Principles of laboratory animal care" (NIH publication no. 85-23, revised 1985) were followed.
Measurements. Cholesteryl ester hydroperoxides were analysed by HPLC, with $234 \mathrm{~nm}$ UV detection and post-column chemiluminescence detection on an LC-8 column (Supelco, $4 \times 250 \mathrm{~mm}$, 5- $\mu \mathrm{m}$ particles; Sigma-Aldrich) and methanol/tert-butyl alcohol $(95 / 5 \mathrm{vol})$ as the eluent, as reported previously but with slight modification [18]. In brief, plasma was extracted with 10 volumes of methanol and 50 volumes of hexane. The hexane phase was removed, dried under $\mathrm{N}_{2}$ gas and redissolved in an eluent for HPLC injection. Liver glutathione content was measured spectrophotometrically using a glutathione reductase recycling assay, as described previously [19].

Hyperinsulinaemic-euglycaemic clamp study. Rats fasted overnight were anaesthetised by intraperitoneal injection of pentobarbital sodium $(60 \mathrm{mg} / \mathrm{kg}$ body weight) and the left jugular and femoral veins were catheterised for blood sampling and infusion respectively. Hyperinsulinaemic-euglycaemic clamp analysis was performed as described previously [17]. The glucose utilisation rate, hepatic glucose production and an estimate of muscle glucose uptake during the clamp (defined as the glucose metabolic index) were calculated as previously described [20].

Glucose uptake into isolated soleus muscle. Rats fasted overnight were anaesthetised and soleus muscles were dissected out and rapidly cut into $20-40 \mathrm{mg}$ strips. The rats were then killed by intracardiac injection of pentobarbital. Isolated soleus muscle was incubated for $20 \mathrm{~min}$ with or without $1.44 \times 10^{-8} \mathrm{~mol} / \mathrm{l}$ human insulin (this concentration is equivalent to $2 \mathrm{mU} / \mathrm{ml}$ ), as described previously [17]. 2-Deoxy glucose uptake into the isolated soleus muscle strips was measured using 2-deoxy-D-[ $\left.{ }^{3} \mathrm{H}\right]$ glucose and $\left[{ }^{14} \mathrm{C}\right]$ manitol as described previously [21].

Preparation of rat adipocytes and measurement of glucose uptake. Isolated rat adipocytes were prepared from epididymal adipose tissue harvested from fasted rats using the collagenase method [22], and 2-deoxy glucose uptake was then assayed as previously described [23].

Adenovirus-mediated gene transfer to 3T3-L1 adipocytes. 3T3L1 fibroblasts were maintained in DMEM supplemented with $10 \%$ donor calf serum and differentiated into adipocytes as previously described [24]. The dominant negative mutant of I $\kappa \mathrm{B}-\alpha$, in which serine residues 32 and 36 were substituted with alanine, was kindly provided by Dr R. Gaynor (University of Texas Southwestern Medical Center at Dallas, Tex., USA). To obtain recombinant adenovirus, pAdeno-X was ligated with cDNA encoding Escherichia coli lacZ and dominant negative $\mathrm{I} \kappa \mathrm{B}$ according to the manufacturer's instructions for the Adeno-X Expression System (Clontech, Palo Alto, Calif., USA). Infection of 3T3-L1 adipocytes with the adenovirus was carried out as described previously [25]. Recombinant adenoviruses were applied at a multiplicity of infection of approximately 200-300 pfu/cell and 3T3-L1 adipocytes infected with lacZ virus were used as a control.

Gel mobility shift assay. Nuclear protein extracts from 3T3-L1 adipocytes were prepared using NE-PER nuclear and cytoplasmic extraction reagents (Pierce Biotechnology, Rockford, Ill., USA) according to the manufacturer's instructions and used for gel mobility shift assay (GMSA). Briefly, 3T3-L1 adipocytes were homogenised in $1 \mathrm{ml}$ of PBS and centrifuged for $10 \mathrm{~min}$ at $500 \times g$ at $4{ }^{\circ} \mathrm{C}$. After removing the supernatant, the pellet was resuspended in $500 \mu$ of Cytoplasmic Extraction Reagent I buffer containing protease inhibitors (1 $600 \mathrm{~mol} / \mathrm{l}$ benzamidine, $0.3 \mathrm{mmol} / \mathrm{l}$ aprotinin, $4.2 \mathrm{~mol} / \mathrm{l}$ leupeptin, $0.2 \mathrm{~mol} / \mathrm{l}$ phenylmethylsulfonyl fluoride), and was incubated 
on ice for $10 \mathrm{~min}$. Then, $27.5 \mu \mathrm{l}$ of Cytoplasmic Extraction Reagent II buffer were added to the sample, which was vortexed and centrifuged at $16000 \times g$ for $5 \mathrm{~min}$. The resultant pellet was resuspended in $250 \mu \mathrm{l}$ of NER buffer, vortexed every 10 minutes for $40 \mathrm{~min}$ and then centrifuged at $16000 \times g$ for $10 \mathrm{~min}$. The supernatant containing nuclear proteins was stored at $-80{ }^{\circ} \mathrm{C}$. For the GMSA, $10 \mu \mathrm{g}$ of nuclear proteins were incubated in binding buffer with 3.5 pmol of double-stranded DNA oligonucleotide containing an NF- $\mathrm{KB}$ consensus-binding sequence labelled with [ $\left.{ }^{32} \mathrm{P}\right]$-ATP using T4 polynucleotide kinase for $30 \mathrm{~min}$ at $37^{\circ} \mathrm{C}$. For supershift analyses, monoclonal antibody against NF- $\mathrm{KB}$ p65 was separately pre-incubated with nuclear extracts at $4{ }^{\circ} \mathrm{C}$ for $20 \mathrm{~min}$ in a total volume of $16 \mu \mathrm{l}$ of binding buffer, followed by incubation with $8 \mu$ of ${ }^{32} \mathrm{P}$ labelled oligonucleotide probe with and without cold oligonucleotide probe at $4{ }^{\circ} \mathrm{C}$ for 20 min using a Nushift Kit (Geneka Biotechnology, Carlsbad, Calif., USA). Protein-DNA complexes were separated from the unbound DNA probe by electrophoresis through $5 \%$ polyacrylamide gels containing $1 \times$ Tris-glycine-EDTA buffer. The gel was dried and exposed to BAS2000 (Fujifilm, Tokyo, Japan).

Glucose uptake into 3T3-L1 adipocytes. 3T3-L1 adipocytes plated in 24-well culture dishes were serum starved for $3 \mathrm{~h}$ in DMEM containing $0.2 \%$ bovine serum albumin, after which they were incubated in Krebs-Ringer phosphate buffer for an additional $45 \mathrm{~min}$, prior to incubation with or without $10^{-6}$ or $10^{-7} \mathrm{~mol} / \mathrm{l}$ insulin for $15 \mathrm{~min}$. The assay was initiated by adding 2-deoxy-D-[3 $\left.{ }^{3} \mathrm{H}\right]$ glucose $\left(1.85 \times 10^{7} \mathrm{~Bq} /\right.$ sample, $\left.0.1 \mathrm{mmol}\right)$ and was terminated 4 min later by washing the cells once with icecold Krebs-Ringer phosphate buffer containing $0.3 \mathrm{mmol} / \mathrm{l}$ phloretin and then twice with ice-cold Krebs-Ringer phosphate buffer. The cells were then solubilised in $0.1 \%$ SDS, and the incorporated radioactivity was determined by scintillation counting [26].

Subcellular fractionation. 3T3-L1 adipocytes were serum starved for $3 \mathrm{~h}$ and incubated with or without $10^{-6} \mathrm{~mol} / \mathrm{l}$ insulin for $15 \mathrm{~min}$. Cells were fractionated as described previously [27]. Briefly, 3T3-L1 adipocytes were resuspended in HES buffer $(255 \mathrm{mmol} / \mathrm{l}$ sucrose, $20 \mathrm{mmol} / \mathrm{l}$ HEPES [pH 7.4], $1 \mathrm{mmol} / \mathrm{l}$ EDTA), homogenised and subjected to differential centrifugation. The supernatants from the following spins were serially removed and pelleted in a Ti70 rotor as follows: $19000 \times g(20 \mathrm{~min}), 41000 \times g(20 \mathrm{~min})$ and $180000 \times g$ (75 min). The first $19000 \times g$ pellet was resuspended, loaded onto a sucrose cushion (1.12 mol/l sucrose, $20 \mathrm{mmol} / 1$ HEPES [pH 7.4], $1 \mathrm{mmol} / \mathrm{l}$ EDTA) and isolated from the interface yielding the plasma membrane fraction as the pellet of a $41000 \times g$ spin $(20 \mathrm{~min})$. The last $180000 \times g$ pellet corresponded to the low-density microsome (LDM) fraction. Subcellular fractionation and measurement of GLUT4 translocation in isolated skeletal muscle and adipocytes from rats were described previously [12]. After resuspension of the pellets in solubilisation buffer, $20 \mu \mathrm{g}$ of each fraction were loaded for western blotting. Proteins in the plasma membrane and LDM fractions were separated by SDS-PAGE, transferred to a polyvinylidene fluoride membrane, immunoblotted with antiGLUT4, anti-IRS-1 or anti-p85 antibodies, and reacted with enhanced chemiluminescence reagent (Amersham Biosciences, Uppsala, Sweden) or subject to immunoprecipitation and PI 3-kinase assay of the immunoprecipitates as previously described [17].

Immunoprecipitation and immunoblotting. In rat experiments, rats fasted overnight were anaesthetised, and within 10-15 min the abdominal cavity was opened, the portal vein exposed, and
$16 \mathrm{ml} / \mathrm{kg}$ body weight of normal saline $(0.9 \% \mathrm{NaCl})$, with or without $10^{-5} \mathrm{~mol} / \mathrm{l}$ human insulin, were injected. After $60 \mathrm{~s}$, hindlimb muscles were removed and immediately homogenised as described previously [28]. In 3T3-L1 experiments, 3T3-L1 adipocytes were serum-starved for $18 \mathrm{~h}$, preincubated with or without $80 \mu \mathrm{mol} / \mathrm{l} \mathrm{BSO}$ for $18 \mathrm{~h}$, then stimulated with or without $10^{-6} \mathrm{~mol} / 1$ insulin for $15 \mathrm{~min}$. The cells were then washed and lysed with lysis buffer as described previously [29]. After centrifugation, the resultant supernatants were used for immunoprecipitation or immunoblotting as described previously [28]. Proteins were visualised with enhanced chemiluminescence and band intensities were quantified with a Molecular Imager GS-525 using Imaging Screen$\mathrm{CH}$ (Bio-Rad Laboratories, Hercules, Calif., USA). In some experiments, 3T3-L1 cells were incubated with $5.8 \mathrm{pmol} / 1$ (equivalent to $10 \mathrm{ng} / \mathrm{dl}$ ) TNF- $\alpha$ or $80 \mu \mathrm{mol} / \mathrm{l} \mathrm{BSO}$ for $18 \mathrm{~h}$, lysed and immunoblotted with anti-IKB antibody.

Phosphatidylinositol 3-kinase activity. After preparing tissue samples as above, IRS-1 was immunoprecipitated, and PI 3-kinase activity in the immunoprecipitates was assayed as previously described [17].

Statistical analysis. Data are expressed as means \pm SE. Comparisons between the two groups were made using unpaired $t$ tests. We considered $p$ values of less than 0.05 to be statistically significant.

\section{Results}

Characterisation of rats studied. Although food intakes were similar in the two groups, the BSO-treated rats had lower body weights than control rats (Table 1). Individual water consumptions did not differ between the two. Systolic and diastolic blood pressures were similar in the two groups of rats. Fasting blood glucose and plasma insulin levels in BSO rats were also similar to those of control rats. Although fasting insulin levels were not elevated in BSO-treated rats as compared with those of controls, we found that

Table 1. Characterisation of BSO-treated rats

\begin{tabular}{lcc}
\hline & Control & BSO \\
\hline Body weight (g) & $320.0 \pm 8.7$ & $284 \pm 4.1^{*}$ \\
Food intake (g/day) & $20.2 \pm 2.4$ & $21.2 \pm 2.3$ \\
Water intake (ml/day) & $38.2 \pm 1.8$ & $36.8 \pm 3.2$ \\
Systolic BP (mm Hg) & $113.5 \pm 4.4$ & $120.7 \pm 3.9$ \\
Diastolic BP (mm Hg) & $83.4 \pm 4.4$ & $87.8 \pm 1.4$ \\
Fasting blood glucose (mmol/l) & $6.12 \pm 0.32$ & $6.32 \pm 0.24$ \\
Randomly fed blood glucose & $8.37 \pm 0.24$ & $8.44 \pm 0.17$ \\
$\quad$ (mmol/l) & & \\
Fasting plasma insulin (pmol/l) & $109 \pm 16$ & $112 \pm 3$ \\
Randomly fed plasma insulin & $188 \pm 17$ & $367 \pm 3^{*}$ \\
$\quad($ pmol/l) & & \\
Glutathione content of liver & $3.2 \pm 0.3$ & $1.1 \pm 0.4^{*}$ \\
$\quad$ Plamol/g tissue) & & \\
$\quad$ hydroperoxide (mmol/l) & $1.38 \pm 0.3$ & $2.72 \pm 0.3^{*}$ \\
\hline
\end{tabular}

Data are means $\pm \mathrm{SE}$; rats in each group, $n=6 ;{ }^{*} p<0.05$ compared with controls 
a

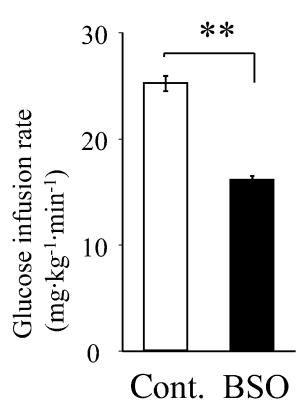

b

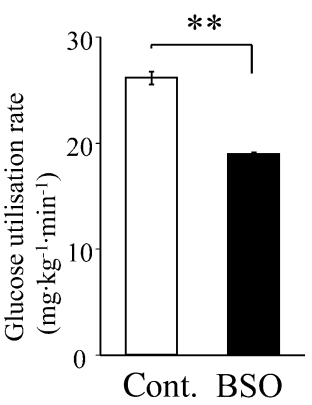

C

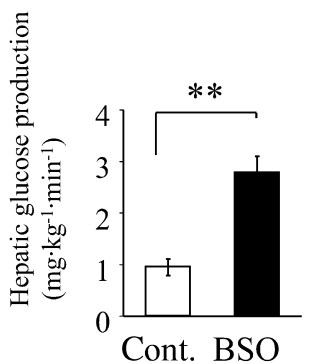

d

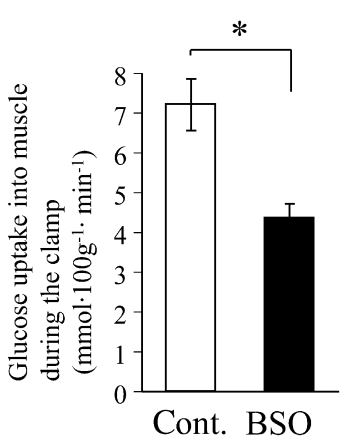

Fig. 1. A hyperinsulinaemic-euglycaemic clamp study. Rats were anaesthetised by intraperitoneal injection of pentobarbital sodium and the left jugular and femoral veins were catheterised for blood sampling and infusion respectively. Hyperinsulinaemic-euglycaemic clamp analysis was performed as described previously [17]. The glucose infusion rate (a), glucose utilisation rate (b), hepatic glucose production (c) and muscle glucose uptake during the clamp (defined as the glucose metabolic index; d) were estimated from hyperinsulinaemic-euglycaemic clamp data. $* p<0.05, * * p<0.01$ compared with the control. Bars represent the means \pm SE of results from four to five rats. Cont. indicates control SpragueDawley rats. BSO indicates rats fed a standard rodent diet with water containing $30 \mathrm{mmol} / \mathrm{l} \mathrm{BSO}$ for 12 days

among well-fed animals, insulin levels in BSO-treated rats were significantly higher than those in controls. To determine the effect of BSO as a glutathione synthase inhibitor, hepatic glutathione content was measured, because glutathione is most abundant in the liver. The glutathione level was significantly lower, by $34 \%$, in the livers of BSO-treated rats than in those of controls. The cholesteryl ester hydroperoxide level in BSO-treated rat plasma was double that in control rats, suggesting that oxidative stress is increased in BSO-treated rats.

Hyperinsulinaemic-euglycaemic clamp study. Wholebody insulin sensitivity was evaluated using a hyperinsulinaemic-euglycaemic clamp technique. Compared with controls, the glucose infusion rate was decreased by $36.2 \%$ and the glucose utilisation rate by $27.6 \%$ during submaximal insulin infusion in BSOtreated rats (Figs. 1a, b). In addition, hepatic glucose production was increased by $29.3 \%$ in BSO-treated rats, suggesting impairment of the ability of insulin to suppress hepatic glucose production (Fig. 1c). Glucose uptake into skeletal muscle during the clamp was decreased by $39.4 \%$ in BSO-treated rats (Fig. 1d). These results suggest that BSO treatment induces insulin resistance both systemically and in skeletal muscle and liver.

Insulin-induced glucose uptake and GLUT4 translocation in BSO-treated rat skeletal muscle and adipocytes. In BSO-treated rats, insulin-induced glucose uptakes

into isolated soleus muscle and adipocytes were reduced by $21.4 \%$ and $47.8 \%$ respectively as compared with the control levels (Figs. 2a, c). Subsequent western blot analysis showed the GLUT4 contents of skeletal muscle and adipocytes to be similar in the two groups (Figs. 2b, d, upper panels), indicating that the impairment of insulin-induced glucose uptake in these tissues from BSO-treated rats was not due to reduced expression of GLUT4 proteins. However, insulin-induced GLUT4 translocation, as assessed by the appearance of GLUT4 in the plasma membrane fraction of skeletal muscle and adipose tissue, was decreased in BSO-treated rats (Figs. 2b, d, lower panels). Microscopic analysis revealed adipocytes from BSO-treated rats to be small, which is consistent with the low body weights of these rats (Fig. 2e), suggesting that insulin resistance in BSO-treated rats is not attributable to adipocyte enlargement.

Impairment of insulin signalling in BSO-treated rat skeletal muscle and adipocytes. Next, we investigated insulin-induced tyrosine phosphorylation of IRS-1, association of PI 3-kinase with IRS-1, and PI 3-kinase activation in skeletal muscle and adipose tissue in vivo by injecting insulin through the portal vein of anaesthetised rats. Protein amount and insulin-induced tyrosine phosphorylation of IRS-1 in skeletal muscle (whole tissue lysates) from BSO-treated rats were similar to those in controls (Fig. 3a, upper panels). Because the insulin signalling in the LDM fraction has been implicated in several insulin actions including insulin-induced glucose uptake $[30,31]$, we carried out subcellular fractionation studies of skeletal muscles from these rats. Subcellular fractionation data showed insulin-induced tyrosine phosphorylation of IRS-1 in the LDM fraction to be significantly decreased in BSO-treated rats as compared with controls, although the IRS-1 protein amount in this fraction was unchanged (Fig. 3a, upper panels). In the cytosol, the amount of IRS-1 and insulin-induced phosphorylation were similar in BSO-treated and control rat muscles (Fig. 3a, upper panels). Next, we investigated the amount of the p85 subunit for PI 3-kinase protein in whole tissue lysates, the LDM fraction and the cytosol (Fig. 3a, middle panels). The amounts of $\mathrm{p} 85$ protein were similar in whole tissue 
a

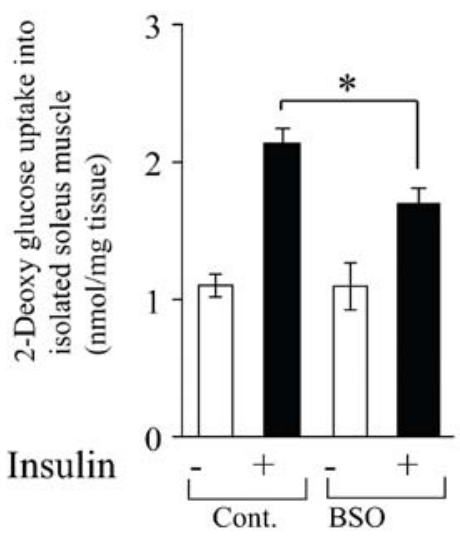

C

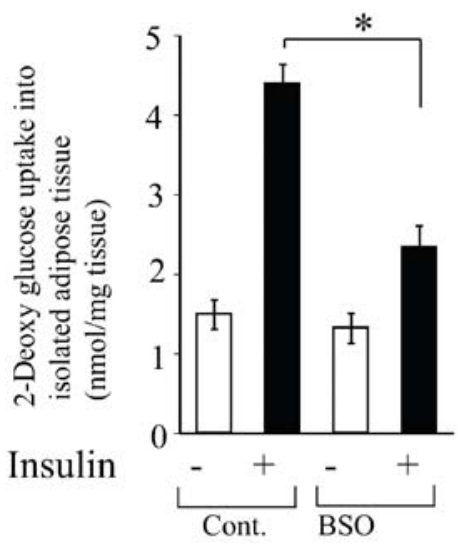

b

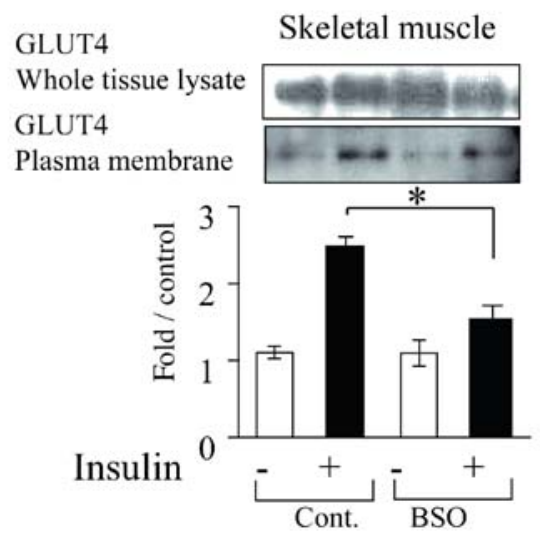

d

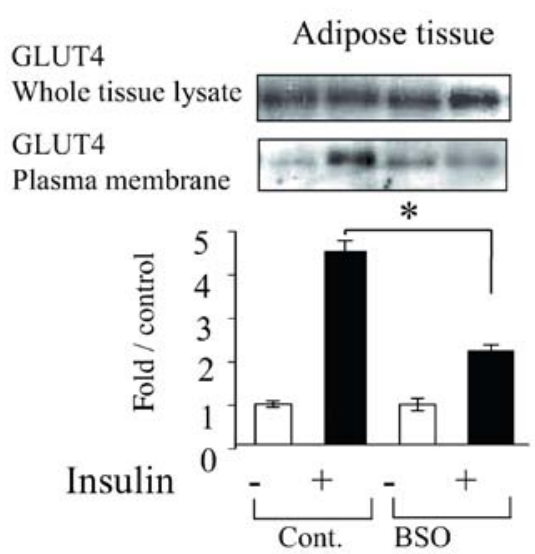

e

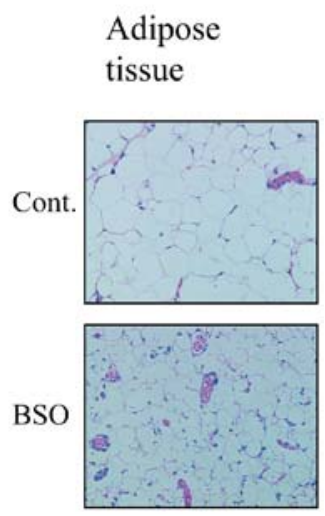

Fig. 2. Insulin resistance in isolated skeletal muscle and adipose tissue in BSO-treated rats. a. 2-Deoxy-glucose uptakes into isolated soleus muscle and adipose tissue (c). Isolated rat soleus muscle was incubated for $20 \mathrm{~min}$ with or without $1.44 \times 10^{-8} \mathrm{~mol} / \mathrm{l}$ human insulin (this concentration is equivalent to $2 \mathrm{mU} / \mathrm{ml}$ ) as described previously [17]. 2-Deoxy-D$\left[1-{ }^{3} \mathrm{H}\right]$ glucose uptake into the isolated soleus muscle strips was measured as described previously [21]. Isolated rat adipocytes were prepared from epididymal adipose tissue harvested from fasted rats using the collagenase method [22], and 2-deoxy glucose uptake was then assayed as previously described [23]. b, d. GLUT4 protein amount in whole tissue lysates (upper panels), the plasma membrane fraction (lower panels) of skeletal muscle (b) and adipose tissue (d) under basal or insulinstimulated conditions. Subcellular fractionation and measurement of GLUT4 translocation of isolated skeletal muscle and adipocytes from rats were described previously [12]. Whole tissue lysates and plasma membrane fractions were subjected to SDS-PAGE followed by immunoblotting with anti-GLUT4 antibody. The data are representative of three independent experiments. Bars depict means $\pm \mathrm{SE}$ of the results from four to six samples. $* p<0.05$ compared with the control under the insulin-stimulated conditions. d. Haematoxylin and eosin stained adipose tissues from control and BSO-treated rats are shown. Cont. indicates control Sprague-Dawley rats. BSO indicates rats fed a standard rodent diet with water containing $30 \mathrm{mmol} / \mathrm{l}$ BSO for 12 days lysates before and after insulin stimulation. However, insulin stimulation induced a p85 increase in the LDM fraction and a decrease in the cytosol, suggesting that insulin stimulates p85 translocation from the cytosol to the LDM fraction. This insulin-induced translocation of p85 was disrupted in BSO-treated rats. Insulininduced increases in IRS-1-associated $\mathrm{p} 85$ protein and PI 3-kinase activity did not differ significantly between whole tissue lysates and the cytosol in either BSO-treated or control rat muscle (Fig. 3a, lower panels). However, both were significantly decreased in the LDM fraction of BSO-treated rats as compared with the controls. We obtained essentially the same results in the adipose tissue of these rats (Fig. 3b). In addition, we confirmed that insulin-induced tyrosine phosphorylation of the insulin receptor and IRS-2, as well as Ser-473 phosphorylation of Akt, in the whole tissue lysates of skeletal muscle and adipose tissue does not differ between BSO-treated and control rats (data not shown). Thus, early insulin-signalling steps were shown to be impaired specifically in the LDM fraction, but not in whole tissue lysates of skeletal muscle and adipose tissue from BSO-treated rats.

Insulin action and insulin signalling in BSO-treated 3T3-L1 adipocytes. To further investigate the impaired step in BSO-induced insulin resistance, 3T3-L1 
a Whole tissue lysate $\quad$ LDM fraction $\quad$ Cytosol
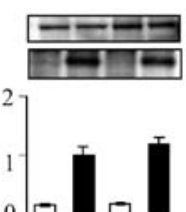
phosphorylation (fold / control)
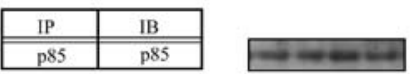

p85 protein amount 2 (fold / control)
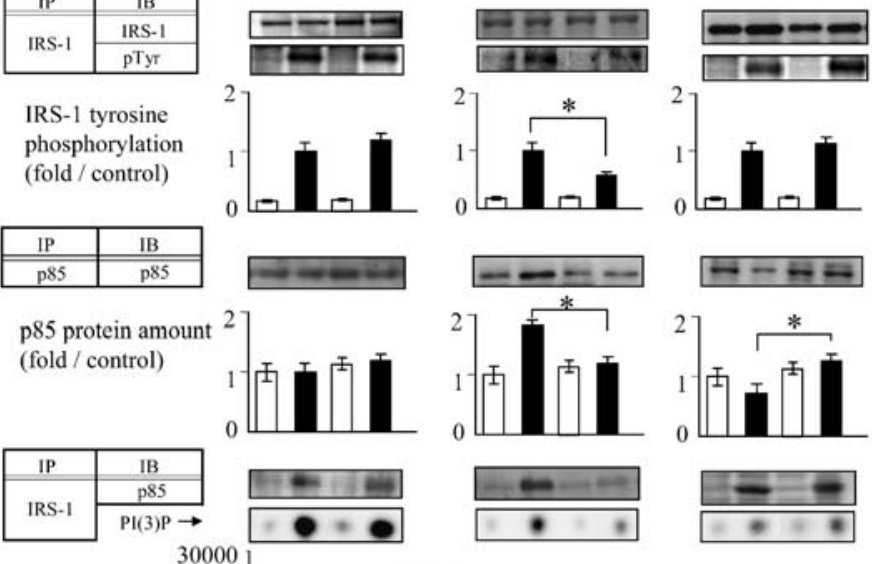

IRS-1-associated 20000

PI 3-kinase

activity (cpm)

Insulin
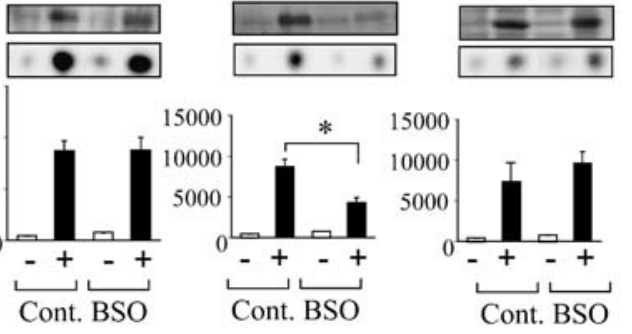

Fig. 3. Insulin signalling in skeletal muscle (a) and adipose tissue (b) from BSO-treated rats. Rats were anaesthetised, the portal vein exposed, and $16 \mathrm{ml} / \mathrm{kg}$ body weight of normal saline, with or without $10^{-5} \mathrm{~mol} / \mathrm{l}$ human insulin, were injected. After $60 \mathrm{~s}$, hindlimb muscles and epididymal fat were removed and immediately homogenised as described previously [28]. After centrifugation, the resultant supernatants were employed for immunoprecipitation or immunoblotting using the indicated antibodies as described previously [28]. Proteins were visualised with enhanced chemiluminescence and band intensities were quantified with a Molecular Imager GS-525 using Imaging Screen-CH (Bio-Rad). Bars depict means \pm SE of the quantitated tyrosine phosphorylation bands, independently obtained in triplicate. Representative spots of PI(3)P are shown in the lower panels and bars depict means \pm SE of PI 3-kinase activity measured in three independent assays. $* p<0.05 \mathrm{com}-$ pared with the control under the insulin-stimulated condition. IP, immunoprecipitation; IB, immunoblotting; pTyr, phosphotyrosine

adipocytes were incubated with $80 \mu \mathrm{mol} / \mathrm{l} \mathrm{BSO}$ for $18 \mathrm{~h}$ [32]. It was reported that BSO treatment of adipocytes markedly decreases cellular glutathione levels and increases reactive oxygen species [15, 32]. Incubation with BSO did not affect the morphology or the viability of 3T3-L1 adipocytes (data not shown). Insulin-induced glucose uptake into 3T3-L1 adipocytes was decreased by $42.5 \%$ in BSO-treated cells (Fig. 4a). In these cells, insulin-induced GLUT4 translocation to the plasma membrane was impaired (Fig. 4b). Next, we determined insulin-induced IRS-1 phosphorylation and PI 3-kinase activation in whole cell lysates, the LDM fraction and the cytosol. As in rats, protein levels and insulin-induced tyrosine phosphorylations of IRS-1 and IRS-1-associated PI b

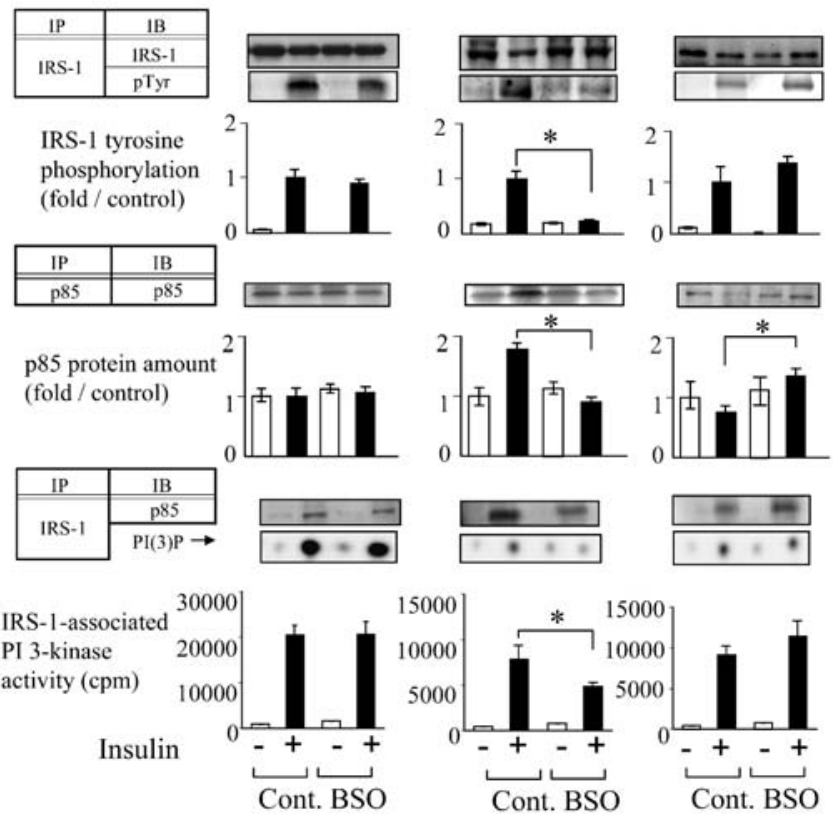

3-kinase were unaffected by BSO treatment (Fig. 4c, upper panel). In control cells and in BSO-treated cells, p85 protein levels did not differ before versus after insulin stimulation. Next, we examined IRS-1 tyrosine phosphorylation and IRS-1 associated PI 3-kinase activity in the LDM fraction and the cytosol. While IRS-1 protein levels did not change after incubation with BSO, insulin-induced IRS-1 tyrosine phosphorylation in the LDM fraction was suppressed by BSO treatment (Fig. 4c, middle panel). The amount of p85 protein was increased in the LDM fraction and decreased in the cytosol after insulin stimulation, indicating that insulin induces p85 translocation from the cytosol to the LDM fraction in control cells. However, the p85 increase in the LDM fraction was clearly disrupted in BSO-treated cells (Fig. 4c, middle panel). In parallel, insulin-stimulation increased IRS-1-associated p85 protein levels and PI 3-kinase activity in the LDM fraction of control but not BSO-treated cells. Thus, BSO treatment disrupts insulin-induced IRS-1 phosphorylation in the LDM fraction and the subcellular redistribution of PI 3-kinase in 3T3-L1 adipocytes.

Inhibition of $N F-\kappa B$ activation improves $B S O$-induced insulin resistance. It is widely known that one potential target of oxidative stress is the activation of transcription factor NF- $\kappa B$ [33]. Oxidative stress and inflammatory cytokine stimulation reportedly activate upper kinase IКB kinase (IKK) which phosphorylates

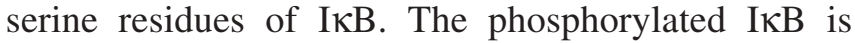
then subject to degradation, leading to translocation of $\mathrm{NF}-\kappa \mathrm{B}$ to the nucleus [34]. To investigate the role of $\mathrm{NF}-\kappa \mathrm{B}$ cascade activation in BSO-induced insulin re- 


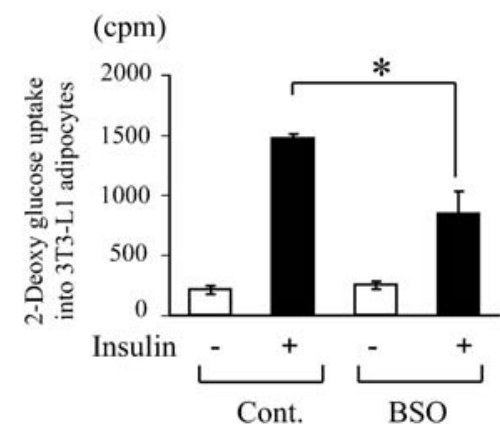

b

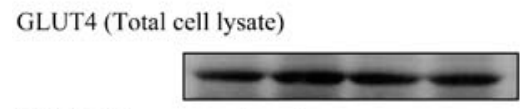

GLUT4 (Plasma membrane)
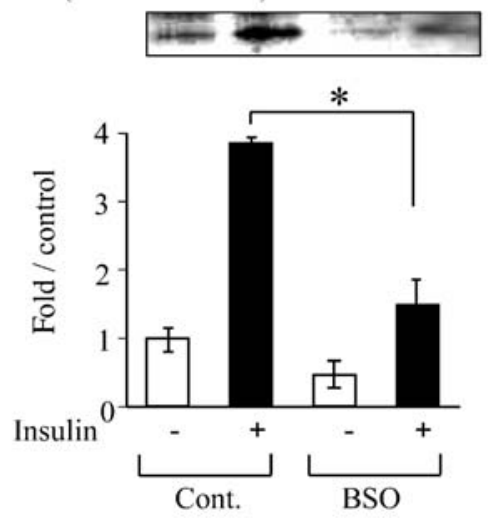

Fig. 4. Effects of BSO treatment on insulin action and insulin signalling in 3T3-L1 adipocytes. a. Insulin-induced 2-deoxy glucose uptake into 3T3-L1 adipocytes. 3T3-L1 adipocytes were serum-starved for $18 \mathrm{~h}$, pre-incubated with or without $80 \mu \mathrm{mol} / \mathrm{l} \mathrm{BSO}$ for $18 \mathrm{~h}$, then incubated with or without $10^{-6} \mathrm{~mol} / 1$ insulin for $15 \mathrm{~min}$. 2-Deoxy glucose uptake was measured as described in Materials and methods. Bars depict means \pm SE of results obtained independently in triplicate. $* p<0.05$ compared with the insulin-stimulated control. b. Recruitment of GLUT4 to the plasma membrane in 3T3-L1 adipocytes with or without BSO pretreatment. 3T3-L1 adipocytes were serum-starved for $18 \mathrm{~h}$, pre-incubated with or without $80 \mu \mathrm{mol} / \mathrm{l} \mathrm{BSO}$ for $18 \mathrm{~h}$, then stimulated with or without $10^{-6} \mathrm{~mol} / \mathrm{l}$ insulin for $15 \mathrm{~min}$. Cells were fractionated as described previously [27]. The cell lysates and plasma membrane fraction were immunoblotted with anti-GLUT4 antibody. Representative immunoblots using anti-GLUT4 antibody are shown. Bars depict means \pm SE of the quantitated bands of the plasma membrane fraction, independently obtained in triplicate. c. IRS-1 phosphorylation and IRS-1-associated PI 3-kinase in
C

\begin{tabular}{|c|c|}
\hline IP & IB \\
\hline \hline \multirow{2}{*}{ IRS-1 } & IRS-1 \\
\cline { 2 - 2 } & $\mathrm{pT} y r$ \\
\hline $\mathrm{p} 85$ & $\mathrm{p} 85$ \\
\hline \multirow{2}{*}{ IRS-1 } & $\mathrm{p} 85$ \\
\cline { 2 - 2 } & $\mathrm{PI}(3) \mathrm{P} \rightarrow$ \\
\hline
\end{tabular}

Whole cell lysate

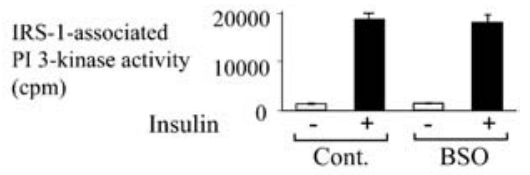

\begin{tabular}{|c|c|}
\hline IP & IB \\
\hline \hline \multirow{2}{*}{ IRS-1 } & IRS-1 \\
\cline { 2 - 2 } & $\mathrm{pT}$ Tyr \\
\hline $\mathrm{p} 85$ & $\mathrm{p} 85$ \\
\hline \multirow{2}{*}{ IRS-1 } & $\mathrm{p} 85$ \\
\cline { 2 - 2 } & $\mathrm{PI}(3) \mathrm{P} \rightarrow$ \\
\hline
\end{tabular}

LDM fraction
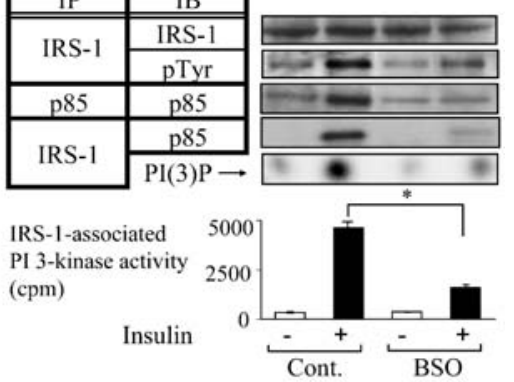

\begin{tabular}{|c|c|}
\hline IP & IB \\
\hline \hline \multirow{2}{*}{ IRS-1 } & IRS-1 \\
\cline { 2 - 2 } & $\mathrm{pTyr}$ \\
\hline $\mathrm{p} 85$ & $\mathrm{p} 85$ \\
\hline \multirow{2}{*}{ IRS-1 } & $\mathrm{p} 85$ \\
\cline { 2 - 2 } & $\mathrm{PI}(3) \mathrm{P} \rightarrow$ \\
\hline
\end{tabular}

Cytosol

IRS-1-associated

PI 3-kinase activity (cpm)

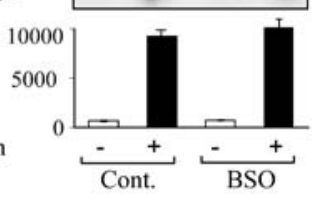

whole cell lysates (upper panels), the LDM fraction (middle panels) and the cytosol (lower panels) in 3T3-L1. 3T3-L1 adipocytes were serum-starved for $18 \mathrm{~h}$, pre-incubated with or without $80 \mu \mathrm{mol} / \mathrm{l} \mathrm{BSO}$ for $18 \mathrm{~h}$, then stimulated with or without $10^{-6} \mathrm{~mol} / \mathrm{l}$ insulin for $15 \mathrm{~min}$. Subcellular fractionation was performed as described in Materials and methods. The whole cell lysates and fractions were used for immunoprecipitation, immunoblotting and PI 3-kinase assay as described previously [28]. Proteins were visualised with enhanced chemiluminescence and band intensities were quantified with a Molecular Imager GS-525. Representative immunoblots are shown in the upper and middle panels and representative spots of $\mathrm{PI}(3) \mathrm{P}$, independently obtained in triplicate, are shown in the lower panel. Bars depict means \pm SE of the quantitated spots of PI(3)P, indicating IRS-1-associated PI 3-kinase activity, independently obtained in triplicate. Cont., control 3T3-L1 adipocytes; BSO, pre-treated with $80 \mu \mathrm{mol} / \mathrm{l} \mathrm{BSO}$ for $18 \mathrm{~h}$. $* p<0.05$ compared with the control under the insulin-stimulated condition

In 3T3-L1 adipocytes, endogenous IאB was degraded by $5.8 \mathrm{pmol} / \mathrm{l}$ (equivalent to $10 \mathrm{ng} / \mathrm{dl}$ ) of TNF- $\alpha$ or $80 \mu \mathrm{mol} / \mathrm{l}$ BSO pre-incubation for $18 \mathrm{~h}$ (Fig. 5a). However, the dominant negative I $\mathrm{BB}$, overexpressed using adenovirus, was not degraded by these treat- sistance, we overexpressed the dominant negative mutant of I $\mathrm{KB}$ in 3T3-L1 adipocytes using adenovirus. This mutant, characterised by the substitution of two serine phosphorylation sites to alanine, is resistant to degradation and inhibits NF- $\kappa \mathrm{B}$-induced transcription. 
a
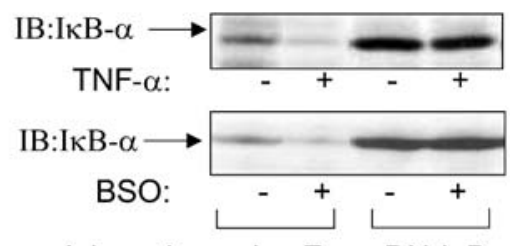

Adenovirus: LacZ DN-IKB

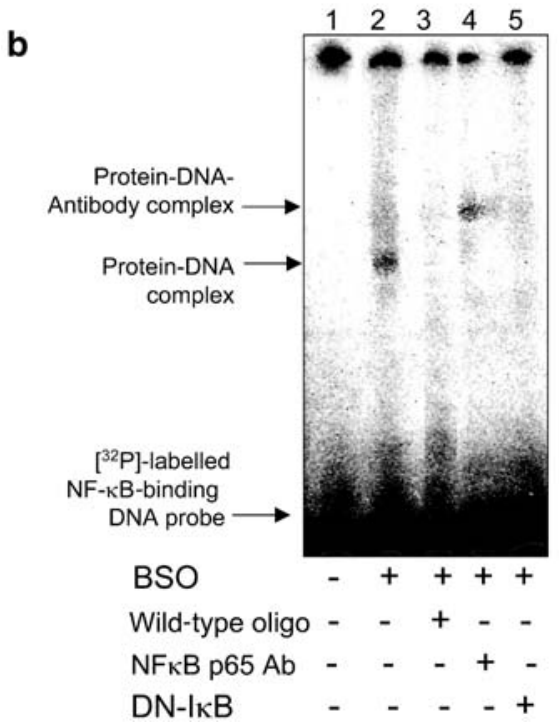

Fig. 5. Dominant negative mutant of IKB. a. Immunoblot of 3T3-L1 adipocytes overexpressing LacZ (control) and dominant negative mutant of $\mathrm{I}-\kappa \mathrm{B}$ adenoviruses. Representative immunoblots with anti-I $\kappa \mathrm{B} \alpha$ antibody of the cells incubated with $5.8 \mathrm{pmol} / \mathrm{l}$ (equivalent to $10 \mathrm{ng} / \mathrm{ml}$ ) TNF- $\alpha$ and $80 \mu \mathrm{mol} / \mathrm{l}$ BSO for $18 \mathrm{~h}$ are shown in the upper and lower panels respectively. b. Gel mobility shift assay (GMSA). 3T3-L1 adipocytes were incubated with (lanes 2-5) or without (lane 1) $80 \mu \mathrm{mol} / 1$ $\mathrm{BSO}$ for $18 \mathrm{~h}$. Dominant negative I $\mathrm{kB}$ was overexpressed in 3T3-L1 adipocytes (lane 5). Nuclear protein extracts from 3T3-L1 adipocytes were prepared as described in Materials and methods. For the GMSA, $10 \mu \mathrm{g}$ of nuclear proteins were incubated in binding buffer with 3.5 pmol of double-stranded DNA oligonucleotide containing an NF- $\kappa$ B consensus binding sequence labelled with [ $\left.{ }^{32} \mathrm{P}\right]-\mathrm{ATP}$ using $\mathrm{T} 4$ polynucleotide kinase, for $30 \mathrm{~min}$ at $37^{\circ} \mathrm{C}$. For supershift analyses, monoclonal antibody against NF- $\kappa \mathrm{B}$ p65 (NF- $\kappa \mathrm{B}$ p65 Ab, lane 4) was separately pre-incubated with nuclear extracts at $4{ }^{\circ} \mathrm{C}$ for $20 \mathrm{~min}$ in a total volume of $16 \mu \mathrm{l}$ of binding buffer, followed by incubation with $8 \mu \mathrm{l}$ of ${ }^{32} \mathrm{P}$-labelled oligonucleotide probe with and without a cold oligonucleotide probe (wild-type oligo, lane 3 ) at $4{ }^{\circ} \mathrm{C}$ for $20 \mathrm{~min}$ using a Nushift Kit (Geneka Biotechnology). Protein-DNA complexes were separated from the unbound DNA probe by electrophoresis through 5\% polyacrylamide gels containing $1 \times$ Tris-glycine-EDTA buffer. The gel was dried and exposed to BAS2000 (Fujifilm, Tokyo, Japan). DN, dominant negative; IB, immunoblotting

ments (Fig. 5a). To investigate whether NF- $\kappa B$ binds to regulatory DNA elements, GMSA was performed using nuclear extracts of 3T3-L1 adipocytes. GMSA revealed nuclear protein extracts from BSO-treated 3T3-L1 adipocytes to contain activated NF- $\mathrm{KB}$ (Fig. 5b, lanes 1 and 2). The band shift was inhibited by unlabelled oligonucleotide corresponding to a
DNA-binding sequence (Fig. 5b, lane 3). In BSOtreated cells, the NF- $\kappa \mathrm{B}$-oligonucleotide complex underwent a supershift in the presence of antibodies against the p65 subunit of $\mathrm{NF}-\kappa \mathrm{B}$, indicating that binding to the oligonucleotide is NF- $\kappa \mathrm{B}$-specific (Fig. 5b, lane 4). In 3T3-L1 adipocytes overexpressing the dominant negative $\mathrm{I} \kappa \mathrm{B}$, the band shift was also inhibited (Fig. 5b, lane 5). These results suggest that $\mathrm{BSO}$ treatment induces NF- $\kappa \mathrm{B}$ translocation and that the dominant negative I $\mathrm{KB}$ blocks $\mathrm{NF}-\kappa \mathrm{B}$ pathway activation.

We next examined the effect of the dominant negative IкB on BSO-induced insulin resistance. Insulininduced glucose uptake was decreased by BSO treatment, while dominant negative I $\mathrm{KB}$ overexpression reversed this decrease (Fig. 6a). Reduction of insulininduced GLUT4 translocation by BSO administration was also reversed by overexpression of the dominant negative IאB (Fig. 6b). BSO treatment decreased insulin-induced IRS-1 phosphorylation and IRS-1-associated p85 and PI 3-kinase activity in the LDM fraction (Fig. 6c, lower panels), but not in whole cell lysates (Fig. 6c, upper panels). However, overexpression of the dominant negative I $\mathrm{B}$ reversed the BSO-induced decreases in IRS-1 phosphorylation and IRS-1-associated p85 and PI 3-kinase activity in the LDM fraction. These results suggest that oxidative stress induces insulin resistance by impairing the normal subcellular distribution of PI 3-kinase, and that the NF- $\kappa \mathrm{B}$ pathway is involved in this process.

\section{Discussion}

In this study we employed BSO, a glutathione synthase inhibitor, to induce oxidative stress in rats and in 3T3-L1 adipocytes. BSO specifically inhibits the first step of glutathione synthesis and decreases glutathione, an important component of the antioxidant defence system [14]. In fact, we confirmed a decreased hepatic glutathione content and an increased plasma lipid hydroperoxide level, indicating increased oxidative stress in BSO-treated rats. Body weight was lower in BSO-treated rats than in controls, which is consistent with a previous report [35]. BSO-treated rats were apparently insulin-resistant, as demonstrated by a hyperinsulinaemic-euglycaemic clamp study and glucose transport assay using isolated skeletal muscle and adipocytes. These results strongly support the hypothesis that increased oxidative stress can lead to insulin resistance in vivo. Although fasting insulin levels were not elevated in BSO-treated rats as compared with controls, we found that among well-fed animals, insulin levels were significantly higher in BSO-treated rats than in controls. Data from the euglycaemic-hyperinsulinaemic clamp study, along with the observed glucose uptake into isolated tissues and insulin levels in well-fed animals, support the 
a

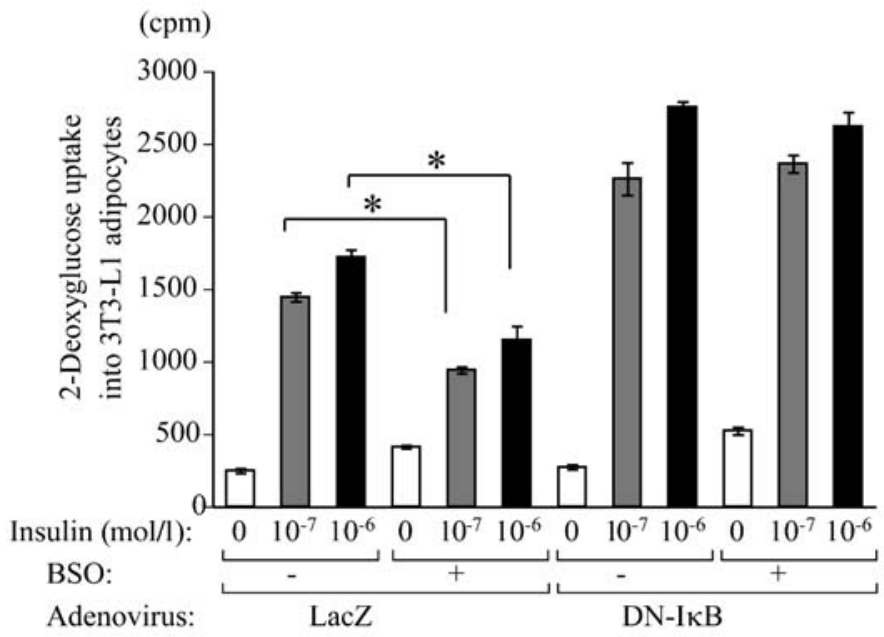

b

GLUT4 (Total cell lysate)

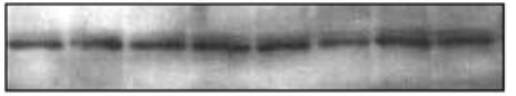

GLUT4 (Plasma membrane)

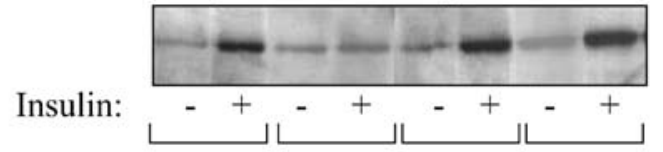

BSO:

Adenovirus: c

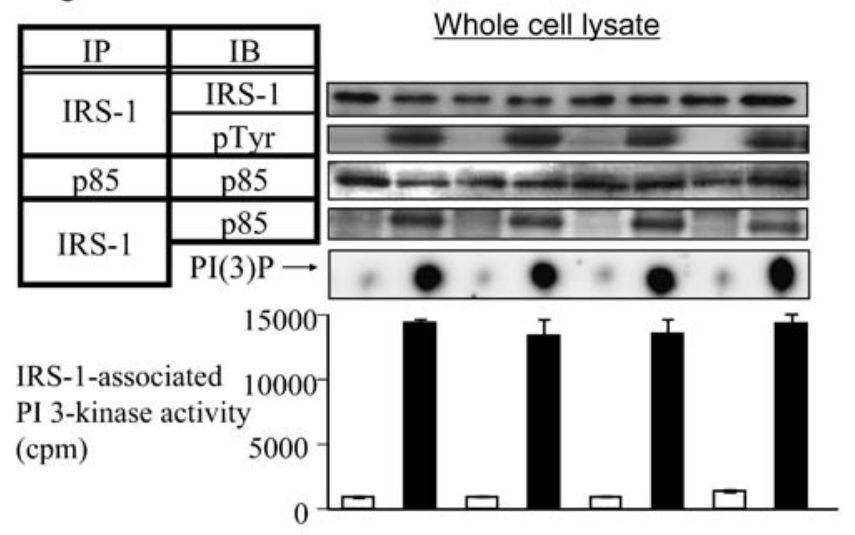

$\underline{\text { LDM fraction }}$
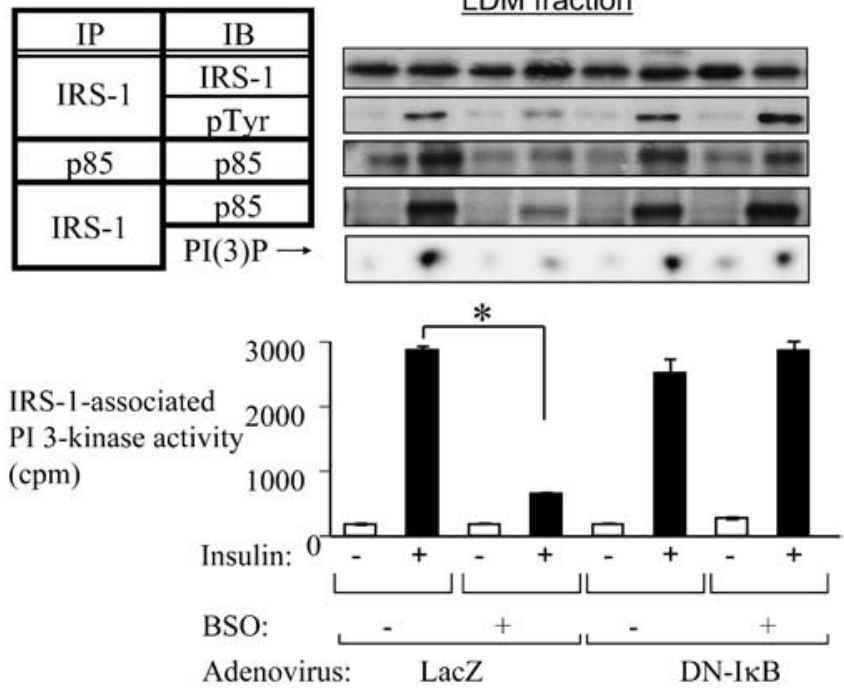

Fig. 6. Effect of dominant negative mutant of $\mathrm{I} \kappa \mathrm{B}$ on insulin action and insulin signalling in BSO-treated 3T3-L1 adipocytes. a. Insulin-induced 2-deoxy glucose uptake into 3T3-L1 adipocytes. Cells overexpressing LacZ (control) and the dominant negative (DN)-I $\kappa \mathrm{B}$ adenovirus with or without $80 \mu \mathrm{mol} / \mathrm{l} \mathrm{BSO}$ for $18 \mathrm{~h}$ were stimulated were stimulated with $0,10^{-7}$ or $10^{-6} \mathrm{~mol} / 1$ insulin for $15 \mathrm{~min}$. Glucose uptake into 3T3-L1 adipocytes was assayed as described in Materials and methods. Bars depict means $\pm \mathrm{SE}$ of results obtained independently in triplicate. $* * p<0.05$ compared to insulin-stimulated $\left(10^{-7}\right.$ and $10^{-6} \mathrm{~mol} / \mathrm{l}$ respectively) control (non BSO-treated) cells. b. Recruitment of GLUT4 to the plasma membrane in 3T3-L1 adipocytes overexpressing LacZ and DN-IאB adenovirus with or without BSO pretreatment. The cell lysates and plasma membrane fraction were immunoblotted with antiGLUT4 antibody. c. IRS-1 tyrosine phosphorylation, p85 protein amount and IRS-1-associated PI 3-kinase in whole cell lysates (upper panels) and the LDM fraction (lower panels) of 3T3-L1 adipocytes overexpressing LacZ and DN-IKB adenovirus with or without BSO pretreatment. 3T3-L1 adipocytes were serum-starved for $18 \mathrm{~h}$, pre-incubated with or without $80 \mu \mathrm{mol} / \mathrm{l} \mathrm{BSO}$ for $18 \mathrm{~h}$, then stimulated with or without $10^{-6} \mathrm{~mol} / \mathrm{l}$ insulin for $15 \mathrm{~min}$. Representative immunoblots and representative spots of $\mathrm{PI}(3) \mathrm{P}$, independently obtained in triplicate, are shown and bars depict means \pm SE of PI 3-kinase activity measured in three independent assays. ${ }^{*} p<0.05$ compared with insulin-stimulated control (non BSO-treated) cells. IB, immunoblotting; IP, immunoprecipitation

conclusion that BSO-treated rats are insulin-resistant. In our experiments, we did not observe the occurrence of overt diabetes with BSO administration, suggesting that this insulin resistance is relatively mild.

A previous report showed no significant difference between BSO-injected rats and controls in terms of insulin-stimulated glucose transport into skeletal muscle [15]. The results of their study contradict our present data demonstrating BSO-induced insulin resistance. We speculate that these different results are attributable to the doses of BSO administered. According to our water consumption data, intake of BSO in $\mathrm{BSO}$-treated rats was approximately $3.5 \mathrm{mmol} \cdot \mathrm{kg}^{-1}$ body weight.day ${ }^{-1}$ in the current study. This is a rather high dose compared with the previous report (2 mmol. $\cdot \mathrm{kg}^{-1}$ body weight $\left.\cdot \mathrm{day}^{-1}\right)$ [15]. Also, the extent of the glutathione decrease was greater in our experiment than in the previous one. In addition, because the previous study did not employ the hyperinsulinaemic-euglycaemic clamp method [15], we believe our picture of insulin resistance in BSO-treated rats to be more accurate.

Insulin-induced IRS phosphorylation and PI 3-kinase activation constitute a critical step in insulin actions such as GLUT4 translocation and glucose uptake [36]. Most insulin-resistant models have been shown 
to have impaired insulin-induced PI 3-kinase activation $[28,37,38]$. However, in the BSO-treated rats used in the current study, neither insulin-induced IRS tyrosine phosphorylation nor PI 3-kinase activation in whole tissue lysates of skeletal muscle and adipose tissue were impaired, despite the presence of insulin resistance. In addition, BSO treatment markedly impaired insulin-induced glucose uptake into 3T3-L1 adipocytes and GLUT4 translocation, while insulininduced IRS-1 tyrosine phosphorylation and IRS-1associated PI 3-kinase activation were unchanged in whole cell lysates of BSO-treated 3T3-L1 adipocytes. A previous report showed $\mathrm{H}_{2} \mathrm{O}_{2}$ exposure of 3T3-L1 adipocytes to inhibit insulin-induced glucose uptake, while having no effects on IRS-1 phosphorylation and PI 3-kinase activation [39]. Furthermore, we previously reported chronically angiotensin-II-infused rats, in which plasma lipid hydroperoxide levels were increased, to be highly insulin-resistant, although insulin-induced IRS-1 phosphorylation and PI 3-kinase activation in skeletal muscle and adipose tissue were not impaired [12]. Thus, insulin resistance with normal insulin-induced PI 3-kinase activation in the whole cell may be a common feature in the models with increased oxidative stress.

Regarding the molecular mechanism of this type of insulin resistance, we consider it necessary to examine the possibility of abnormalities in the subcellular distribution of PI 3-kinase. This is based on several reports showing IRS-1 phosphorylation and PI 3-kinase activation specifically in the LDM fraction, though not in whole cell lysates, to be important for insulin action $[30,31]$. We speculate that the insulin-induced increase in IRS-1 phosphorylation in the LDM fraction leads to recruitment of the p85 subunit for PI 3-kinase to that fraction. Previous reports have shown that $\mathrm{H}_{2} \mathrm{O}_{2}$ exposure reduces IRS- 1 tyrosine phosphorylation and PI 3-kinase activation in the LDM fraction in 3T3-L1 adipocytes $[39,40]$. In the current study, insulin-induced IRS-1 tyrosine phosphorylation in the LDM fraction was demonstrated to be significantly decreased in both BSO-treated rat muscle and adipose tissues and in BSO-treated 3T3-L1 cells. We showed clearly that insulin induces p85 translocation from the cytosol to the LDM fraction in rat muscle, adipose tissue and 3T3-L1 cells and that BSO treatment disrupts this process. Taking our results and those of previous reports together, we consider this disruption of the normal subcellular redistribution of PI 3-kinase to be one of the important mechanisms underlying oxidative-stress-induced insulin resistance.

The activation of transcription factor NF- $\kappa B$ has been shown to be a target of oxidative stress [33]. For example, direct exposure to oxidants such as $\mathrm{H}_{2} \mathrm{O}_{2}$ activates NF- $\kappa \mathrm{B}$ [41], while NF- $\kappa \mathrm{B}$ activation can be inhibited by addition of antioxidants such as a vitamin E derivative [42] and lipoic acid [43]. To clarify the contribution of NF- $\kappa \mathrm{B}$ cascade activation to oxida- tive-stress-induced insulin resistance, we utilised the dominant negative I $\mathrm{B}$ B. This mutant is a degradationresistant form of $I \kappa B$ that prevents $N F-\kappa B$ from translocating into the nucleus and is widely used to block cytokine-induced NF- $\kappa \mathrm{B}$ activation [44]. Indeed, we confirmed that this mutant is not degraded by TNF- $\alpha$ and that BSO stimulation blocks NF- $\kappa \mathrm{B}$ from translocating into the nucleus. Blocking the $\mathrm{NF}-\kappa \mathrm{B}$ cascade by overexpressing dominant negative $\mathrm{I} \kappa \mathrm{B}$ had a preventive effect against the decrease in insulin-induced glucose uptake and GLUT4 translocation caused by BSO treatment in 3T3-L1 adipocytes. We observed higher glucose uptake in dominant negative IKB-overexpressing cells than in LacZ control cells. We suggest a possible explanation: dominant negative I $\mathrm{K} B$ inhibits the effects of a small amount of inflammatory cytokines secreted by adipocytes. In addition, BSO-induced decreases in IRS-1 tyrosine phosphorylation in the LDM fraction and recruitment of PI 3-kinase to that fraction were also normalised. These results suggest that $N F-\kappa B$ activation is involved in the impaired subcellular redistribution of PI 3-kinase and the insulin resistance induced by BSO treatment.

The precise mechanism linking NF- $\mathrm{\kappa B}$ activation and abnormal subcellular redistribution of PI 3-kinase remains unclear. One possible mechanism of inhibited insulin signalling involves NF- $\mathrm{NB}$-activated transcription of inflammatory cytokines such as TNF- $\alpha$ and interleukin- 6 . NF- $\kappa \mathrm{B}$ plays an important role in regulating inflammatory responses $[45,46]$ and activation of NF- $\kappa \mathrm{B}$ may induce inappropriate inflammatory responses, possibly disrupting insulin signalling. Alternatively, PI 3-kinase activation is reportedly necessary for $N F-\kappa B$ activation [47, 48]. Aberrant $\mathrm{NF}-\kappa \mathrm{B}$ activation may disrupt the PI 3-kinase pathway via a negative feedback mechanism. An anti-inflammatory agent, salicylate, which stabilises IКB via inhibition of IKK and suppression of NF- $\kappa \mathrm{B}$ activation, was shown to restore lipid-induced insulin resistance $[49,50]$. Because IKK reportedly induces serine phosphorylation of IRS-1, it is possible that BSO activates IKK, resulting in down-regulation of IRS-1 tyrosine phosphorylation in the LDM fraction and impairment of PI 3-kinase recruitment to the LDM fraction.

In summary, our results suggest that oxidative stress induces insulin resistance by impairing insulininduced IRS-1 phosphorylation in the LDM fraction and subcellular redistribution of PI 3-kinase, and that $\mathrm{NF}-\kappa \mathrm{B}$ activation is involved in this process. Our present study provides evidence that the NF- $\kappa \mathrm{B}$ pathway plays a role in the pathogenesis of oxidativestress-induced insulin resistance. Judging from our results and those of previous studies, strategies designed to limit inappropriate activation of NF- $\kappa \mathrm{B}$ may be an effective approach to treating insulin resistance. 
Acknowledgements. The dominant negative mutant of IкB was kindly provided by Dr Richard Gaynor (University of Texas Southwestern Medical Center at Dallas, Tex., USA). The authors are indebted to Naomasa Kakiya of the University of Tokyo for assistance in various areas of this study.

\section{References}

1. Betteridge DJ (2000) What is oxidative stress? Metabolism 49 [Suppl 1]:3-8

2. Reaven GM, Lithell H, Landsberg L (1996) Hypertension and associated metabolic abnormalities - the role of insulin resistance and the sympathoadrenal system. N Engl J Med 334:374-381

3. Tuck ML (1990) Metabolic considerations in hypertension. Am J Hypertens 3:355S-365S

4. Baynes JW (1991) Role of oxidative stress in development of complications in diabetes. Diabetes 40:405-412

5. Paolisso G, D'Amore A, Volpe C et al. (1994) Evidence for a relationship between oxidative stress and insulin action in non-insulin-dependent (type II) diabetic patients. Metabolism 43:1426-1429

6. Jones AF, Winkles JW, Jennings PE et al. (1988) Serum antioxidant activity in diabetes mellitus. Diabetes Res 7:89-92

7. Paolisso G, Di Maro G, Pizza G et al. (1992) Plasma GSH/GSSG affects glucose homeostasis in healthy subjects and non-insulin-dependent diabetics. Am J Physiol 263:E435-E440

8. Paolisso G, Balbi V, Volpe C et al. (1995) Metabolic benefits deriving from chronic vitamin $\mathrm{C}$ supplementation in aged non-insulin dependent diabetics. J Am Coll Nutr $14: 387-392$

9. Paolisso G, Di Maro G, Galzerano D et al. (1994) Pharmacological doses of vitamin $\mathrm{E}$ and insulin action in elderly subjects. Am J Clin Nutr 59:1291-1296

10. Rajagopalan S, Kurz S, Munzel T et al. (1996) Angiotensin II-mediated hypertension in the rat increases vascular superoxide production via membrane NADH/NADPH oxidase activation. Contribution to alterations of vasomotor tone. J Clin Invest 97:1916-1923

11. Schnackenberg CG, Wilcox CS (1999) Two-week administration of tempol attenuates both hypertension and renal excretion of 8 -Iso prostaglandin f2alpha. Hypertension 33:424-428

12. Ogihara T, Asano T, Ando K et al. (2002) Angiotensin II-induced insulin resistance is associated with enhanced insulin signalling. Hypertension 40:872-879

13. Shimosawa T, Ogihara T, Matsui H et al. (2003) Deficiency of adrenomedullin induces insulin resistance by increasing oxidative stress. Hypertension 41:1080-1085

14. Meister A (1983) Selective modification of glutathione metabolism. Science 220:472-477

15. Khamaisi M, Kavel O, Rosenstock M et al. (2000) Effect of inhibition of glutathione synthesis on insulin action: in vivo and in vitro studies using buthionine sulfoximine. Biochem J 349:579-586

16. Vaziri ND, Wang XQ, Oveisi F, Rad B (2000) Induction of oxidative stress by glutathione depletion causes severe hypertension in normal rats. Hypertension 36:142-146

17. Ogihara T, Asano T, Ando K et al. (2001) Insulin resistance with enhanced insulin signalling in high-salt diet-fed rats. Diabetes 50:573-583

18. Yamamoto Y (1994) Chemiluminescence-based high-performance liquid chromatography assay of lipid hydroperoxides. Methods Enzymol 233:319-324
19. Anderson ME (1985) Determination of glutathione and glutathione disulfide in biological samples. Methods Enzymol 113:548-555

20. James DE, Burleigh KM, Kraegen EW (1986) In vivo glucose metabolism in individual tissues of the rat. Interaction between epinephrine and insulin. J Biol Chem 261:63666374

21. Hansen P, Gulve EA, Holloszy JO (1994) Suitability of 2-deoxyglucose for in vitro measurement of glucose transport activity in skeletal muscle. J Appl Physiol 76:979985

22. Rodbell M (1964) Metabolism of isolated fat cells. I. Effects of hormones on glucose metabolism and lipolysis. J Biol Chem 239:375-380

23. Olefsky JM (1975) Effect of dexamethasone on insulin binding, glucose transport, and glucose oxidation of isolated rat adipocytes. J Clin Invest 56:1499-1508

24. Fujishiro M, Gotoh Y, Katagiri H et al. (2001) MKK6/3 and p38 MAPK pathway activation is not necessary for insulin-induced glucose uptake but regulates glucose transporter expression. J Biol Chem 276:19800-19806

25. Katagiri H, Asano T, Ishihara H et al. (1996) Overexpression of catalytic subunit p110alpha of phosphatidylinositol 3-kinase increases glucose transport activity with translocation of glucose transporters in 3T3-L1 adipocytes. J Biol Chem 271:16987-16990

26. Asano T, Kanda A, Katagiri H et al. (2000) p110beta is up-regulated during differentiation of 3T3-L1 cells and contributes to the highly insulin-responsive glucose transport activity. J Biol Chem 275:17671-17676

27. Satoh S, Nishimura H, Clark AE et al. (1993) Use of bismannose photolabel to elucidate insulin-regulated GLUT4 subcellular trafficking kinetics in rat adipose cells. Evidence that exocytosis is a critical site of hormone action. J Biol Chem 268:17820-17829

28. Anai M, Funaki M, Ogihara T et al. (1998) Altered expression levels and impaired steps in the pathway to phosphatidylinositol 3-kinase activation via insulin receptor substrates 1 and 2 in Zucker fatty rats. Diabetes 47:1323

29. Sakoda H, Ogihara T, Anai M et al. (1999) No correlation of plasma cell 1 overexpression with insulin resistance in diabetic rats and 3T3-L1 adipocytes. Diabetes 48:13651371

30. Anai M, Ono H, Funaki M et al. (1998) Different subcellular distribution and regulation of expression of insulin receptor substrate (IRS)-3 from those of IRS-1 and IRS-2. J Biol Chem 273:29686-29692

31. Kriauciunas KM, Myers MG Jr, Kahn CR (2000) Cellular compartmentalization in insulin action: altered signaling by a lipid-modified IRS-1. Mol Cell Biol 20:6849-6859

32. Lu B, Ennis D, Lai R et al. (2001) Enhanced sensitivity of insulin-resistant adipocytes to vanadate is associated with oxidative stress and decreased reduction of vanadate $(+5)$ to vanadyl (+4). J Biol Chem 276:35589-35598

33. Schreck R, Albermann K, Baeuerle PA (1992) Nuclear factor kappa B: an oxidative stress-responsive transcription factor of eukaryotic cells (a review). Free Radic Res Commun 17:221-237

34. Siebenlist U, Franzoso G, Brown K (1994) Structure, regulation and function of NF-kappa B. Annu Rev Cell Biol 10:405-455

35. Leeuwenburgh C, Ji LL (1995) Glutathione depletion in rested and exercised mice: biochemical consequence and adaptation. Arch Biochem Biophys 316:941-949

36. Czech MP (1995) Molecular actions of insulin on glucose transport. Annu Rev Nutr 15:441-471 
37. Saad MJ, Folli F, Kahn JA, Kahn CR (1993) Modulation of insulin receptor, insulin receptor substrate-1, and phosphatidylinositol 3-kinase in liver and muscle of dexamethasone-treated rats. J Clin Invest 92:2065-2072

38. Cusi K, Maezono K, Osman A et al. (2000) Insulin resistance differentially affects the PI 3-kinase- and MAP kinase-mediated signalling in human muscle. J Clin Invest 105:311-320

39. Rudich A, Tirosh A, Potashnik R, Hemi R, Kanety H, Bashan N (1998) Prolonged oxidative stress impairs insulin-induced GLUT4 translocation in 3T3-L1 adipocytes. Diabetes 47:1562-1569

40. Tirosh A, Potashnik R, Bashan N, Rudich A (1999) Oxidative stress disrupts insulin-induced cellular redistribution of insulin receptor substrate-1 and phosphatidylinositol 3kinase in 3T3-L1 adipocytes. A putative cellular mechanism for impaired protein kinase B activation and GLUT4 translocation. J Biol Chem 274:10595-10602

41. Schreck R, Rieber P, Baeuerle PA (1991) Reactive oxygen intermediates as apparently widely used messengers in the activation of the NF-kappa B transcription factor and HIV-1. EMBO J 10:2247-2258

42. Suzuki YJ, Packer L (1993) Inhibition of NF-kappa B activation by vitamin $\mathrm{E}$ derivatives. Biochem Biophys Res Commun 193:277-283
43. Sen CK, Packer L (1996) Antioxidant and redox regulation of gene transcription. FASEB J 10:709-720

44. Yamamoto Y, Gaynor RB (2001) Therapeutic potential of inhibition of the NF-kappaB pathway in the treatment of inflammation and cancer. J Clin Invest 107:135-142

45. Baeuerle PA, Henkel T (1994) Function and activation of NF-kappa B in the immune system. Annu Rev Immunol 12:141-179

46. Barnes PJ, Karin M (1997) Nuclear factor-kappaB: a pivotal transcription factor in chronic inflammatory diseases. N Engl J Med 336:1066-1071

47. Sizemore N, Leung S, Stark GR (1999) Activation of phosphatidylinositol 3-kinase in response to interleukin-1 leads to phosphorylation and activation of the NF-kappaB p65/RelA subunit. Mol Cell Biol 19:4798-4805

48. Reddy SA, Huang JH, Liao WS (2000) Phosphatidylinositol 3-kinase as a mediator of TNF-induced NF-kappa B activation. J Immunol 164:1355-1363

49. Kim JK, Kim YJ, Fillmore JJ et al. (2001) Prevention of fat-induced insulin resistance by salicylate. J Clin Invest 108:437-446

50. Yuan M, Konstantopoulos N, Lee J et al. (2001) Reversal of obesity- and diet-induced insulin resistance with salicylates or targeted disruption of Ikkbeta. Science 293:16731677 